\title{
Effect of the presence of Polycystic Ovary Syndrome related features on Anti-Mullerian Hormone and Androstenedione levels in adolescents with or without menstrual irregularity
}

\section{Nurcan HANEDAN}

Division of Pediatric Endocrinology and Metabolism, Celal Bayar University

\section{Betul Ersoy ( $\sim$ betul_e@hotmail.com )}

Manisa Celal Bayar University: Manisa Celal Bayar Universitesi https://orcid.org/0000-0003-1696-8406

\section{Candost HANEDAN}

Department of Obstetrics and Gynecology, Merkez Efendi State Hospital

\section{Beyhan Cengiz Özyurt}

Department of Public Health, Celal Bayar University

\section{Fatma TANELi}

Celal Bayar University: Manisa Celal Bayar Universitesi

\section{Research Article}

Keywords: adolescents, Polycystic ovary syndrome, anti-Mullerian Hormone, androstenedione

Posted Date: January 27th, 2022

DOI: https://doi.org/10.21203/rs.3.rs-1089402/v1

License: (c) (i) This work is licensed under a Creative Commons Attribution 4.0 International License. Read Full License

Version of Record: A version of this preprint was published at Archives of Gynecology and Obstetrics on March 30th, 2022. See the published version at https://doi.org/10.1007/s00404-022-06505-4. 


\section{Abstract \\ Purpose}

To determine the variation in Anti-Mullerian Hormone (AMH) and Androstenedione (A4) concentrations in adolescent girls, with or without menstrual cycle disorder in relation to phenotypic features of PCOS.

\section{Methods}

Adolescent girls ( $n=129)$, age range 14-19 years, were recruited in the cohort study. All participants were in the 4th or 5th year after menarche. Sixty-eight had menstrual irregularities, usually oligomenorrhea (OM), and 61 had regular menstruation (RM). AMH and A4 concentrations were measured. Hirsutism was recorded. Polycystic ovarian morphology (PCOM) was evaluated by transabdominal pelvic ultrasonography. Polycystic ovary syndrome (PCOS) features were defined according to Rotterdam consensus criteria.

\section{Results}

$\mathrm{AMH}$ and $\mathrm{A} 4$ were significantly higher in adolescent girls with $\mathrm{OM}$ than in girls with $\mathrm{RM}(p<0.05)$. A4 and body mass index (BMI) of adolescents with OM was significantly higher in those with hirsutism than those without hirsutism ( $p=0.01$ and 0.008 , respectively). There was a positive correlation between A4 and BMI (r: 0.327, p<0.01). Logistic regression showed that the frequency of OM in the presence of PCOM was 10.8 times (95\% Cl 2.04-12.09) compared to those without PCOM. The highest $\mathrm{AMH}$ concentrations were found in girls with $\mathrm{OM}$, hirsutism, and PCOM $(\mathrm{p}<0.05)$.

\section{Conclusions}

$\mathrm{AMH}$ and $\mathrm{A} 4$ are elevated in adolescents with oligomenorrhoea. High A4 is more prominent in the presence of hirsutism and is associated with increased BMI. PCOM, increases the likelihood of oligomenorrhea by about 10 times. AMH increase as the combination of clinical features of PCOS increases in adolescents with menstrual irregularity.

\section{Introduction}

Menstruation pattern is an important indicator of possible fertility, and current and potential female health [1]. Persistent menstrual cycle irregularity may increase the risk of cardiovascular disease [1,2]. Most adolescent girls have menstrual irregularity, which may be due to immaturity of the hypothalamic pituitary gonadal axis, in the first three years after menarche $[3,4]$. It has been shown in many countries that menstrual cycle irregularities are the most common complaint, even in girls 2-3 years after menarche and oligomenorrhoea (OM) is the most common menstrual cycle disorder [5].

Polycystic ovary syndrome (PCOS), one of the most common causes of OM in adolescents, is defined using a variety of criteria, including menstrual irregularity, hyperandrogenism, and polycystic ovarian morphology (PCOM) [6, 7]. Since clinical features of PCOS may be seen in normal puberty, its diagnosis is difficult in the adolescent period [6-8]. If OM persists three years after menarche, it is difficult to differentiate OM due to PCOS from normal physiology [9]. Hirsutism, which is not specific for PCOS and may be due to various reasons [10]. PCOM criteria are problematic in adolescents because in this age group follicle count using abdominal ultrasound may not always be accurate and ovarian volume may be slightly larger than in adults $[11,12]$.

Anti-Mullerian Hormone (AMH) may be useful in the diagnosis of PCOS and detection of PCOM [13]. However, studies emphasize the necessity of improving the accuracy and standardization of the assays and establishing internationally 
approved cut-off levels for different ages in order to use AMH as a marker in the diagnosis of PCOS [13, 14]. In addition, 14 Delta androstenedione (A4) is the immediate precursor of testosterone, which is directly synthesized in the adrenal and ovaries. There are studies demonstrating that serum A4 levels are more sensitive than testosterone as an indicator of PCOS-related androgen excess, but there are limited numbers [15].

In this study, AMH and A4 levels were compared in adolescent girls with and without OM according to the presence or absence of phenotypic features of PCOS. The aim was to determine the changes in AMH and A4 concentrations in the presence or absence of menstrual cycle disorder in adolescent girls, with regard to the phenotypic features of PCOS present, and thus extend the existing criteria by presenting a new perspective in the differential diagnosis of adolescent PCOS.

\section{Participants And Methods Study design and population}

This prospective, cross-sectional and comparative study was approved by the ethics committee of our university and the directorate of national education in Manisa, in Turkey. A questionnaire consisting of questions about the age of menarche, menstrual and socioeconomic characteristics was applied to 1000 adolescent girls studying in Manisa high schools. Among these girls, a group with oligomenorrhea and a group with regular menstruation were randomly selected and consent was obtained from them and their families to participate in the study. Adolescent girls suffering from chronic illnesses and taking any medication were excluded from the study. The age of menarche of all girls was recorded, and girls with at least four years post-menarche were included in the study. Girls were asked for a menstrual pattern. OM was considered. As in adults, girls whose menstrual cycles were between 21 and 40 days were considered to have a normal menstrual pattern $[6,16]$. The research protocol was approved by the local Ethics Committee of the University.

Blood samples were taken fasting during the early follicular phase (days 3-5 of the menstrual period). Girls with oligomenorrhea who no menstruation during the study period were excluded from the study. Thus, 129 adolescent girls, aged 14-19 years, were included in the study 68 of them had oligomenorrhea. 61 adolescent girls had regular menstruation. Height and weight were measured by standard methods. Body mass index (BMI) for each subject was calculated using the following formula: weight $(\mathrm{kg}) /$ height $\left(\mathrm{m}^{2}\right)$. Anthropometric data were evaluated according to Standard Deviation Scores (SDS) $[6,17,18]$.

\section{Definitions}

\section{Oligomenorrhea}

During adolescence, a cycle length up to 40 days may be considered normal, with longer menstrual cycles resulting in only four to nine periods in a year, indicating oligomenorrhea $[6,16]$.

\section{Hirsutism}

defined as excessive terminal hair growth in a male pattern distribution in women. Those with Ferriman-Gallwey (FG) score of over 6 were recorded as having hirsutism. [19]. Hirsutism recorded as present or absent.

Ultrasonography. Trans-abdominal ultrasound measurements were performed by a single observer. The exam was performed with a 5-MHz trans-abdominal probe using a General Electric Voluson 730 expert 2003, USA. PCOM definition was made as 12 or more follicles with a diameter of 2-9 mm in one or both ovaries and / or ovarian volume> $10 \mathrm{ml}$, according to the Rotterdam consensus. (8). Ovarian volume was calculated using the formula for a prolate ellipsoid: $0.52 \times$ 
length $\times$ width $\times$ thickness. However, data of patients were not recorded individually and PCOM was considered as present or absent.

$\mathrm{AMH}$ and $\mathrm{A} 4$ levels were evaluated by considering the criteria defined by the Rotterdam consensus for PCOS diagnosis (oligo ovulation, clinical hyperandrogenism and appearance of polycystic ovaries by ultrasound) [8].

\section{Biochemical Analysis}

Blood samples were centrifuged at $1500 \times \mathrm{g}$ for $10 \mathrm{~min}$ within one hour of collection. Hemolytic, lipemic, and icteric serum samples and samples with insufficient volume were excluded from the study.

$\mathrm{AMH}$ concentrations were assessed by electrochemiluminescence immunoassay method on the UniCel Dxl 800 analyser (Beckman Coulter, California, USA). Samples were processed in a single batch according to the manufacturer's instructions. AMH measurement range of the assay was $0.02-24 \mathrm{ng} / \mathrm{mL}$. Internal quality control samples were included in the assay run and intra-assay coefficients of variation (CVs) values were obtained from the measurements. Intra-assay CVs were $1.6 \%$ and inter assay CV was $2.6 \%$, for the $\mathrm{AMH}$ assay.

A4 concentrations were assessed by electrochemiluminescence immunoassay method on Immulite 2000 XPI analyser (Siemens, Eschborn, Germany). Samples were processed in a single batch according to the manufacturer's instructions. A4 analytical sensitivity was $0.3 \mathrm{ng} / \mathrm{mL}$. Internal quality control samples were included in the assay run and intra-assay coefficients of variation (CVs) values were obtained from the measurements. Intra-assay CVs were calculated as $6.4 \%$ and inter assay CV was calculated as 7.7.\% for the A4 assay.

\section{Statistical analysis}

Data analysis was performed using SPSS for Windows, version 15 software (IBM Inc., Armonk, NY, USA). Values given as mean \pm standard deviation (SD) and percentage. The normality of the distributions was evaluated using the KolmogorovSmirnov test. The two-independent samples $t$-test was used to compare normally distributed variable means between the groups. Data among three or more data sets were compared by Kruskal-Wallis analysis. Mann-Whitney-U test was used to compare two groups for non-Gaussian variables. Categorical variables were assessed using the $\chi^{2}$ test. Pearson's correlation coefficients were computed to assess any linear relation between the variables. Logistic regression models were used to predict the frequency of oligomenorrhea, the presence of PCOS clinical features, and the impact of AMH and A4 concentrations. Receiver operating characteristic (ROC) curve analysis was used to identify the AMH value with the highest sensitivity and specificity when the presence of the three typical clinical features of PCOS were considered.

\section{Results}

The mean age of adolescent girls with $\mathrm{OM}$ was $17.1 \pm 0.97$ years, and $17.0 \pm 0.94$ years for those with RM. The mean age of the two groups was similar $(p=0.659)$. Anthropometric parameters and hormone concentration in whole cohort with and without oligomenorrhea are shown in Table 1. The mean age of menarche of girls with and without OM was similar $(p>0.05)$. Although BMI was higher in girls with OM compared to those without $\mathrm{OM}$, this was not significant, no significant difference was found between the two groups in terms of anthropometric parameters $(p>0.05)$. Mean AMH and A4 concentrations were significantly higher in adolescent girls with $\mathrm{OM}$ than girls with $\mathrm{RM}(p<0.001$ and $p=0.018$, respectively). 
Table 1

Anthropometric parameters and hormone concentration in girls with OM and RM

\begin{tabular}{|c|c|c|c|c|c|c|}
\hline & $\begin{array}{l}\text { Menarcheal age } \\
\text { (year) }\end{array}$ & $\begin{array}{l}\text { Height } \\
\text { SDS }\end{array}$ & $\begin{array}{l}\text { BMI } \\
\left(\mathrm{kg} / \mathrm{m}^{2}\right)\end{array}$ & BMI SDS & $\begin{array}{l}\text { A4 levels } \\
\text { (ng/ml) }\end{array}$ & $\begin{array}{l}\text { AMH level } \\
(\mathrm{ng} / \mathrm{ml})\end{array}$ \\
\hline $\begin{array}{l}\text { Girls with OM } \\
(\mathrm{n}: 68)\end{array}$ & $12.58 \pm 1.05$ & $-0.14 \pm 1.1$ & $22.7 \pm 4.4$ & $0.29 \pm 1.1$ & $2.6 \pm 1.3$ & $4.9 \pm 2.9$ \\
\hline $\begin{array}{l}\text { Girls with RM } \\
(\mathrm{n}: 61)\end{array}$ & $12.59 \pm 1.01$ & $-0,19 \pm 1.0$ & $21.5 \pm 3.6$ & $-0.03 \pm 1.2$ & $2.1 \pm 0.9$ & $3.3 \pm 1.4$ \\
\hline$p$ value & 0.813 & 0.785 & 0.09 & 0.110 & $0.018^{*}$ & $<0.01 *$ \\
\hline
\end{tabular}

PCOM was detected on ultrasound (US) in $84.0 \%(n=42)$ of the adolescent girls with OM but only $16 \%(n=8)$ of those with regular menstruation. This difference was significant $(p<0.001)$. Girls with regular and irregular menses were compared as grouped according to the presence of PCOM (Table 2., Figure 1a.). Only AMH levels were significantly different between the groups $(p<0.01)$. AMH levels in girls both with OM + PCOM and OM without PCOM had significantly higher than girls with RM and PCOM ( $p=0.017)$. The significant difference in AMH level increased between girls with OM and PCOM and girls with RM without PCOM ( $p$ <0.001). However, AMH levels did not differ significantly between girls with OM and PCOM and girls with OM and without PCOM ( $\mathrm{p}=0.739)$. When we evaluated the whole cohort according to the presence of PCOM without considering the menstrual pattern, there was no significant difference between the two groups in any of the parameters $(p>0.05)$.

Table 2

Age, anthropometric and hormonal parameters according to the presence of PCOM

\begin{tabular}{|c|c|c|c|c|c|c|}
\hline Parameters & $\begin{array}{l}\text { a OM without } \\
\text { PCOM (n:26) }\end{array}$ & $\begin{array}{l}\text { b OM with } \\
\text { PCOM (n:42) }\end{array}$ & $\begin{array}{l}\text { c RM with } \\
\text { PCOM (n:8) }\end{array}$ & $\begin{array}{l}{ }^{d} \text { RM without } \\
\text { PCOM (n:53) }\end{array}$ & $\begin{array}{l}p \\
\text { value }\end{array}$ & $\begin{array}{l}\text { Group } \\
\text { differences } ¥\end{array}$ \\
\hline Age (years) & $17.3 \pm 0.8$ & $16.9 \pm 1.0$ & $16.6 \pm 0.8$ & $17.0 \pm 0.9$ & 0.352 & - \\
\hline Height SDS & $-0.02 \pm 1.2$ & $-0.21 \pm 1.0$ & $-0.06 \pm 0.9$ & $-0.21 \pm 1.0$ & 0.907 & - \\
\hline $\begin{array}{l}\text { BMI } \\
\left(\mathrm{kg} / \mathrm{m}^{2}\right)\end{array}$ & $23.9 \pm 5.0$ & $21.9 \pm 4.0$ & $23.1 \pm 5.9$ & $21.2 \pm 3.3$ & 0.161 & - \\
\hline BMISDS & $0.46 \pm 1.0$ & $0.18 \pm 1.1$ & $0.48 \pm 1.9$ & $-0.11 \pm 1.0$ & 0.191 & - \\
\hline MA (years) & $12.6 \pm 1.2$ & $12.5 \pm 0.9$ & $12.4 \pm 1.2$ & $12.5 \pm 0.9$ & 0.833 & - \\
\hline $\mathrm{A} 4(\mathrm{ng} / \mathrm{ml})$ & $2.6 \pm 1.2$ & $2.6 \pm 1.4$ & $2.4 \pm 0.9$ & $2.1 \pm 0.8$ & 0.177 & - \\
\hline $\begin{array}{l}\mathrm{AMH} \\
(\mathrm{ng} / \mathrm{ml})\end{array}$ & $4.7 \pm 3.3$ & $5.0 \pm 2.7$ & $2.8 \pm 0.9$ & $3.3 \pm 1.5$ & $<0.01^{*}$ & $\begin{array}{l}b>c, b>d \\
a>c, a>d\end{array}$ \\
\hline $\begin{array}{l}{ }^{*} p \leq 0.05 \text { is } \mathrm{s} \\
\text { Menarcheal } \\
\text { A4: } 1-4 \text { Delta }\end{array}$ & $\begin{array}{l}\text { hificant for Kru } \\
\text { e, OM: oligom } \\
\text { ndrostenedion }\end{array}$ & $\begin{array}{l}\text { allis test, } ¥: \mathrm{M} \\
\text { a, RM: regular } \\
\text { Anti-Mulleria }\end{array}$ & $\begin{array}{l}\text { hitney U test } \\
\text { truation, BM } \\
\text { none, }\end{array}$ & $\begin{array}{l}\text { are presented } \\
\text { y mass index, }\end{array}$ & $\begin{array}{l}\mathrm{n} \pm \mathrm{SD} \\
\text { andard }\end{array}$ & $\begin{array}{l}\text { A: } \\
\text { viation score, }\end{array}$ \\
\hline
\end{tabular}

Hirsutism was $26.4 \%$ (n:18) in girls with OM. None of the adolescent girls with RM had hirsutism. Girls with irregular and regular menstruation were divided into 3 groups according to the presence of hirsutism (Table 3, figure 1b). A4 and AMH levels and BMI and BMISDS were significantly different between the three groups $(p<0.05)$. AMH levels were found to be significantly higher in OM girls with and without hirsutism than in girls with RM without hirsutism $(p=0.001$ and $p=0.014$ respectively). AMH levels were not different between girls with $\mathrm{OM}$ with and without hirsutism $(p=0.182)$. A4 levels, BMI, 
and BMISDS in adolescent girls with $\mathrm{OM}$ and hirsutism were significantly higher compared to those with OM without hirsutism and RM without hirsutism $(p<0.01)$. When we evaluated the whole cohort according to the presence of hirsutism without considering the menstrual pattern, $\mathrm{AMH}, \mathrm{A} 4$ levels, BMI and BMI SDS in girls with hirsutism differed significantly than in those without hirsutism ( $p=0.012, p<0.01, p=0.002$ and 0.002 , respectively).

Table 3

Age, anthropometric and hormonal parameters according to the presence of hirsutism

\begin{tabular}{|c|c|c|c|c|c|}
\hline Parameters & $\begin{array}{l}\text { OM without hirsutism } \\
\text { (n:50) }\end{array}$ & $\begin{array}{l}\text { b OM with hirsutism } \\
(n: 18)\end{array}$ & $\begin{array}{l}\text { c RM without hirsutism } \\
\text { (n:61) }\end{array}$ & $\begin{array}{l}p \\
\text { value }\end{array}$ & $\begin{array}{l}\text { Group } \\
\text { differences } ¥\end{array}$ \\
\hline Age (years) & $17.0 \pm 0.9$ & $17.2 \pm 0.9$ & $17.0 \pm 0.9$ & 0.698 & - \\
\hline Height SDS & $-0.17 \pm 1.1$ & $-0.04 \pm 1.1$ & $-0.19 \pm 1.0$ & 0.994 & - \\
\hline $\begin{array}{l}\text { BMI } \\
\left(\mathrm{kg} / \mathrm{m}^{2}\right)\end{array}$ & $21.6 \pm 3.5$ & $25.6 \pm 5.5$ & $21.4 \pm 3.7$ & $0.006^{*}$ & $b>a, b>c$ \\
\hline BMISDS & $0.04 \pm 1.0$ & $0.9 \pm 1.1$ & $-0.03 \pm 1.1$ & $0.008^{*}$ & $b>a, b>c$ \\
\hline MA (years) & $12.6 \pm 1.1$ & $12.4 \pm 0.8$ & $12.5 \pm 1.0$ & 0.501 & \\
\hline $\mathrm{A} 4(\mathrm{ng} / \mathrm{ml})$ & $2.2 \pm 1.0$ & $3.7 \pm 1.4$ & $2.1 \pm 0.9$ & $<0.01^{*}$ & $\begin{array}{l}b>c, b>a \\
a=c\end{array}$ \\
\hline $\begin{array}{l}\mathrm{AMH} \\
(\mathrm{ng} / \mathrm{ml})\end{array}$ & $4.7 \pm 3.0$ & $5.6 \pm 2.7$ & $3.3 \pm 1.4$ & $0.02 *$ & $\begin{array}{l}a>c, b>c \\
a=b\end{array}$ \\
\hline
\end{tabular}

The adolescent girls with OM were divided into four groups: those with OM only (Group 1, $\mathrm{n}=18$ ); those with OM and hirsutism (Group 2, n=8); those with OM and PCOM (Group 3, n=32); and those with OM, hirsutism and PCOM (Group 4, $\mathrm{n}=10$ ). Adolescent girls with RM were divided into 2 groups: those with RM with PCOM (Group 5, n:8); those with RM only (Group 6, n:53). Mean BMI and BMI SDS were significantly higher in adolescent girls with hirsutism than in girls with and without only menstrual irregularity $(p<0.05)$ (Table 4., Figure 2.). Girls with PCOM + hirsutism + OM had the highest mean $\mathrm{AMH}$ level, and AMH levels were significantly higher than all other groups $(\mathrm{p}<0.05)$ (Table 4.) Mean A4 levels in girls with were also significantly higher than in girls with and without only menstrual irregularity $(p<0.05)$. 
Table 4

Anthropometric parameters and hormones by number of clinical features of PCOS in adolescent girls with and without oligomenorrhea (OM).

\begin{tabular}{|c|c|c|c|c|c|c|c|c|}
\hline Parameters & $\begin{array}{l}\text { a OM+ } \\
\text { PCOM+ } \\
\text { hirsutism } \\
\text { (n:10) }\end{array}$ & $\begin{array}{l}\text { b } \\
\text { OM+PCOM } \\
(n: 32)\end{array}$ & $\begin{array}{l}{ }^{c} \text { OM } \\
\text { +hirsutism } \\
(\mathrm{n}: 8)\end{array}$ & $\begin{array}{l}\text { d OM } \\
\text { only } \\
\text { (n:18) }\end{array}$ & $\begin{array}{l}\text { e } \\
\text { RM+PCOM } \\
(n: 8)\end{array}$ & $\begin{array}{l}{ }^{f} \text { RM only } \\
(n: 53)\end{array}$ & $\begin{array}{l}P \\
\text { Value }\end{array}$ & $\begin{array}{l}\text { Group } \\
\text { differences } ¥\end{array}$ \\
\hline Age (years) & $17.0 \pm 1.0$ & $16.9 \pm 1.0$ & $17.5 \pm 0.9$ & $17.2 \pm 0.8$ & $16.6 \pm 0.8$ & $17.0 \pm 0.9$ & 0.622 & - \\
\hline Height SDS & $-0.4 \pm 0.9$ & $-0.13 \pm 1.0$ & $-0.06 \pm 0.9$ & $-0.26 \pm 1.2$ & $-0.06 \pm 0.9$ & $-0.21 \pm 1.0$ & 0.463 & - \\
\hline $\begin{array}{l}\mathrm{BMI} \\
\left(\mathrm{kg} / \mathrm{m}^{2}\right)\end{array}$ & $24.6 \pm 5.8$ & $21.1 \pm 2.8$ & $26.9 \pm 5.2$ & $22.6 \pm 4.3$ & $23.1 \pm 5.9$ & $21.2 \pm 3.3$ & $0.026^{\star}$ & $c>d, f$ \\
\hline BMI SDS & $0.88 \pm 1.4$ & $-0.03 \pm 1.0$ & $1.1 \pm 0.7$ & $0.18 \pm 1.0$ & $0.48 \pm 1.9$ & $-0.11 \pm 1.0$ & $0.042^{\star}$ & $a>f, c>d, f$ \\
\hline MA (years) & $12.1 \pm 0.8$ & $12.6 \pm 0.9$ & $12.7 \pm 0.7$ & $12.6 \pm 1.3$ & $12.4 \pm 1.2$ & $12.5 \pm 0.9$ & 0.619 & - \\
\hline $\mathrm{A} 4(\mathrm{ng} / \mathrm{ml})$ & $3.7 \pm 1.5$ & $2.2 \pm 1.1$ & $3.6 \pm 1.4$ & $2.1 \pm 0.8$ & $2.4 \pm 0.9$ & $2.1 \pm 0.8$ & $0.002^{\star}$ & $\begin{array}{l}a>b, f, d, \\
c>b, d, f\end{array}$ \\
\hline $\begin{array}{l}\text { AMH } \\
(\mathrm{ng} / \mathrm{ml})\end{array}$ & $6.8 \pm 2.2$ & $4.5 \pm 2.6$ & $4.1 \pm 2.6$ & $5.0 \pm 3.6$ & $2.8 \pm 0.9$ & $3.3 \pm 1.5$ & $0.002^{\star}$ & $a>e, b, f . b>f$ \\
\hline
\end{tabular}

A negative correlation was found between menarcheal age and $\mathrm{AMH}$ concentration and menarcheal age and $\mathrm{BMI}$ in the whole cohort ( $r-0.206, p=0.01$ and $r-0.183, p=0.03$, respectively). There was also a significant positive relationship between $\mathrm{A} 4$ and $\mathrm{BMI}(\mathrm{r} 0.269, p=0.02)$ and $\mathrm{AMH}$ and $\mathrm{A} 4(\mathrm{r}: 0.415, \mathrm{p}<0.01)$. When correlations in girls with $\mathrm{OM}$ were investigated, there were a negative correlation between $\mathrm{BMI}$ and $\mathrm{AMH}(\mathrm{r}-0.375, p=0.002)$ and a positive correlation between A4 and BMI and BMI SDS ( $r 0.327, p=0.006$ and $r=0.390, p=0.001$, respectively), and AMH and A4 (r:0.456, $p<0.01)$ but no correlation was found between menarcheal age and BMI $(p>0.05)$. In adolescent girls with regular menstruation, only the negative correlation between menarcheal age and BMI was detected $(r-0.287, p=0.02)$. In these girls, the relationship between $\mathrm{AMH}$ and $\mathrm{A} 4$ disappeared.

To investigate the effect of different variables that were associated with the presence of $\mathrm{OM}$, a logistic regression model was created to evaluate the independent risks. In the model the frequency of $\mathrm{OM}$ in the model was found to be 1.38 times $(95 \% \mathrm{Cl} 1.11-1.7)$ with elevated $\mathrm{AMH}, 3.67$ times $(95 \% \mathrm{Cl} 1.0-13.1)$ with hirsutism, and 10.8 times greater $(95 \% \mathrm{Cl} 2.04-12.09)$ with the presence of PCOM.

Since the 10 girls with $\mathrm{OM}$, hirsutism and PCOM had the highest AMH concentrations, AMH concentration was investigated with ROC curve analysis. The cut off value for $\mathrm{AMH}$ with the highest specificity and sensitivity values was $6.26 \mathrm{ng} / \mathrm{mL}$ with a $72 \%$ sensitivity and an $86 \%$ specificity. In the ROC analysis, the values under the curve for androstenedione concentration were not significant, therefore the cut-off value could not be obtained (AUC: $=0.592, p=0.07)$

\section{Discussion}

In this study, AMH and A4 levels were evaluated according to the presence of PCOS clinical features in adolescent girls with and without menstrual cycle irregularities. AMH levels, which are reported to be useful for the diagnosis of PCOS in adult women [14], were found to be significantly higher in adolescent girls with oligomenorrhea than those without. Similar results were obtained for A4 levels. However, the increase in AMH level was more marked than the increase in A4. Adolescents, with or without menstrual cycle disorders, could have the clinical features of PCOS. AMH levels varied in 
adolescent girls according to the presence of PCOS features. As the clinical features of PCOS increased in adolescent girls with oligomenorrhea, AMH levels also increased significantly.

In the present study, adolescent girls with oligomenorrhea had serum AMH and A4 level that were significantly greater than girls with RM in the whole cohort. In our study, as in most previous studies [20, 21], we confirmed that AMH levels are increased in adolescent girls with PCOS-related features, especially in those with oligomenorrhea. In addition, the significant relationship between $\mathrm{AMH}$ and $\mathrm{A} 4$ levels in oligomenorrheic girls in our study was consistent with the results of previous adult and adolescent studies $[22,23]$. Irregular menstruation, especially oligomenorrhea, is one of the most common features of PCOS, and it is believed to often first manifest peri-pubertally [4]. Irregular menstruation usually occurs due to anovulation. One year after menarche, $85 \%$ of menstrual cycles are anovulatory, while this rate drops to $25 \%$ six years after menarche [24]. The adolescent girls who participated in our study were in the fourth or fifth year after menarche, that is, at a time when the rate of anovulatory cycles is reported to have dropped. High AMH levels in girls with $\mathrm{OM}$ suggests the rate of anovulatory cycles may be high in girls with $\mathrm{OM}$. This finding from the present study is in agreement with the report of Ortega et a/ who showed that AMH concentrations are higher in early post-menarcheal girls than in ovulatory women, and girls with more ovulatory cycles have lower AMH levels [25]. Cycle intervals are prolonged due to the presence of anovulatory cycles in patients with PCOS. In addition, considering that high AMH levels may be a supportive marker for the diagnosis of PCOS, girls with OM increased the probability of PCOS occurring in our study.

PCOM, one of the features of PCOS, may be characteristic of physiological puberty and subsides when regular menses begin $[8,23]$. In our study, PCOM was common in girls with oligomenorrhea, but it was also present in girls with RM. PCOM was highly prevalent in girls with OM. In addition, the odds ratio of PCOM being associated with OM was approximately 11 times that of girls with normal menstruation. In previous studies, researchers claimed that the presence of PCOM increased the level of $\mathrm{AMH}$ and emphasized that these levels were highly correlated with the number of follicles in the ovaries in adult women. [11, 26]. Similar results were revealed in a recent adolescent study [21]. Villarroel et al. showed that AMH levels were elevated in the presence of PCOM, even in girls with regular menstruation [27]. In our study, a significant increase in $\mathrm{AMH}$ levels was found in the presence of PCOM in girls with OM. However, AMH levels were also high in girls with OM who did not have PCOM. Presence of PCOM does not increase AMH level in adolescent girls with RM. A4 levels do not change significantly in the presence of PCOM even if there is oligomenorrhea. This is in line with the suggestion of Teede et al in a systematic review, who reported that AMH was not clinically applicable and useful in detecting PCOM [14].

Hirsutism is the clinical manifestation of hyperandrogenism in PCOS. In our study, the frequency of hirsutism was $27.9 \%$ in girls with $\mathrm{OM}$ and $7.8 \%$ in girls with RM. Various androgens, including serum total testosterone (tT), free testosterone (fT), androstenedione (A4), dehydroepiandrosterone sulfate (DHEAS), and calculated free androgen index (FAl) have been used to detect biochemical hyperandrogenism (BH) in PCOS [28]. Some previous studies have suggested that high A4 concentrations are a sensitive indicator for PCOS-related androgen excess [7, 15]. In our study, A4 concentrations were assessed for $\mathrm{BH}$ and found to be significantly higher in girls with $\mathrm{OM}$ compared to girls with RM. In addition, although a positive relationship was found between $\mathrm{A} 4$ and $\mathrm{AMH}$ in girls with oligomenorrhea, this relationship was not found in girls with RM. When the girls were sub-grouped mean A4 concentrations were increased in the presence of hirsutism in girls with $\mathrm{OM}$. These findings indicate that $\mathrm{A} 4$ is an important $\mathrm{BH}$ indicator. Girls with hirsutism were more likely to also have $\mathrm{OM}$. These results suggest that the presence of hirsutism and OM are appropriate screening criteria for PCOS in adolescent girls, as previously described by Villarroel et al [23].

Adrenal androgens have been associated with metabolic parameters related to obesity in PCOS [28]. In present study. girls with hirsutism were significantly more likely to have an increased BMI. In addition, the detection of a positive relationship between BMI and androstenedione levels and the disappearance of this relationship in girls with RM suggested that the increase in androstenedione levels triggered the development of obesity. Although previous studies have demonstrated a relationship between hyperandrogenemia (total testosterone, and dehydroepiandrosterone) and obesity in adolescent girls with PCOS [29], we believe that this is the first report of a similar relationship between androstenedione and BMI. 
When we discriminated phenotypes of adolescent girls with oligomenorrhea and regular menstruation according to the presence of PCOS features, we found that girls with oligomenorrhea and hirsutism and PCOM, i.e. 3 key features of PCOS, had the highest $\mathrm{AMH}$ levels. This group was used to identify the AMH cut-off value by ROC curve analysis. One of the limitations of our study is that we could not recommend our cut-off value for $\mathrm{AMH}$ as a conclusion, since there were only 10 adolescent girls in this group. Our results also demonstrated that AMH concentrations in adolescent girls varied according to the PCOS phenotype. Thus, if $\mathrm{AMH}$ measurement is to be used for the diagnosis of PCOS, it would be necessary to obtain cut-off values specific for each phenotype. In accordance with our study, Gupta et al. reported that $\mathrm{AMH}$ levels showed heterogeneity in different PCOS phenotypes and higher AMH levels in more severe phenotypes [30].

As a conclusion, this study confirmed that the concentration of $\mathrm{AMH}$ is increased in adolescent girls with PCOS features. This increase is particularly evident in the presence of oligomenorrhea. Although A4 levels are high in the oligomenorrheic adolescent, it is more pronounced in the presence of hirsutism and is associated with increased BMI. While polycystic morphology in the ovaries increases the incidence of oligomenorrhea approximately 10 times, only the presence of PCOM does not increase the level of $\mathrm{AMH}$. AMH levels vary according to the presence of PCOS phenotypic features. AMH levels increase as the combination of phenotypic features of PCOS increases in adolescent girls. In this case, in order to use $\mathrm{AMH}$ levels to aid in the diagnosis of PCOS, it would be necessary to identify separate robust cut-off values for each of the four phenotypes.

\section{Abbreviations}

AMH: Anti-Mullerian Hormone, A4: 1-4 Delta androstenedione, BMI: Body Mass Index, OM: oligomenorrhea, PCOM: Polycystic ovarian morphology, PCOS: Polycystic ovary syndrome, RM: Regular menstruation, SDS: Standard deviation score

\section{Declarations}

Acknowledgements: We thank Mr Jeremy Jones for his contribution to the English grammar used in this article.

Funding: This work was supported by scientific research projects committee of our university.

Ethics approval: The study was conducted in accordance with the principles of the Declaration of Helsinki and was approved by the Ethics in Research Committee of the School of Medicine of the Celal Bayar University of Manisa.

Informed consent: Informed consent was obtained from all individual participants included in the study.

Consent to participate: All participants provided written informed consent.

\section{Author contributions:}

Nurcan Hanedan: Study concept, study design, material acquisition, data collection, literature search, writing, Betül Ersoy: study design, supervision, critical reviewing, literature search, data analysis and interpretation, writing, Candost Hanedan: ultrasonographic evaluation of adolescent girls, Beyhan Cengiz Özyurt: the statistical analysis of the study, Fatma Taneli: the biochemical analysis of the study.

\section{Disclosure statement}

The authors declare that they have no competing interests.

\section{References}


1. Toffol E, Koponen P, Luoto R, Partonen T (2014) Pubertal timing, menstrual irregularity, and mental health: results of a population-based study.Arch Womens Ment Health17:127-135

2. Solomon CG, Hu FB, Dunaif A, Rich-Edwards JE, Stampfer MJ, Willett WC, Speizer FE, Manson JE (2002) Menstrual cycle irregularity and risk for future cardiovascular disease.J Clin Endocrinol Metab.87:2013-2017

3. Sun BZ, Kangarloo T, Adams JM, Sluss PM, Welt CK, Chandler DW, Zava DT, McGrath JA, Umbach DM, Hall JE, Shaw ND (2019) Healthy Post-Menarchal Adolescent Girls Demonstrate Multi-Level Reproductive Axis Immaturity.J Clin Endocrinol Metab104:613-623

4. Carlson LJ, Shaw ND (2019)Development of Ovulatory Menstrual Cycles in Adolescent Girls. J Pediatr Adolesc Gynecol32:249-253

5. Agarwal A, Venkat A (2009) Questionnaire Study on Menstrual Disorders in Adolescent Girls in Singapore.J Pediatr Adolesc Gynecol22:365-371

6. American Academy of Pediatrics Committee on Adolescence; American College of Obstetricians and Gynecologists Committee on Adolescent Health Care, Diaz A, Laufer MR, Breech LL (2006) Menstruation in Girls and Adolescents: Using the Menstrual Cycle as a Vital Sign.Pediatrics118:2245-2250

7. Dabadghao P (2019) Polycystic Ovary Syndrome in Adolescents. Best Pract Res Clin Endocrinol Metab 33(3):101272

8. Rotterdam ESHRE/ASRM-sponsored PCOS consensus workshop group (2004) Revised 2003 consensus on diagnostic criteria and long-term health risks related to polycystic ovary syndrome (PCOS). Hum Reprod 19:41-47

9. Rosenfield RL (2015) The diagnosis of polycystic ovary syndrome in adolescents. Pediatrics 136:1154-1165

10. Lucky AW, McGuire J, Rosenfield RL, Lucky PA, Rich BH (1983) Plasma androgens in women with acne vulgaris.J Invest Dermatol81:70-74

11. Dewailly D, Lujan ME, Carmina E, Cedars MI, Laven J, Norman RJ, Escobar-Morreale HF (2014) Definition and significance of polycystic ovarian morphology: a task force report from the Androgen Excess and Polycystic Ovary Syndrome Society. Hum Reprod Update 20:334-352

12. Kenigsberg LE, Agarwal C, Sin S, Shifteh K, Isasi CR, Crespi R, Ivanova J, Coupey SM, Heptulla RA, Arens R (2015) Clinical utility of magnetic resonance imaging and ultrasonography for diagnosis of polycystic ovary syndrome in adolescent girls.Fertil Steril104:1302-1309

13. Asanidze E, Kristesashvili J, Pkhaladze L, Khomasuridze A (2019) The value of anti-Mullerian hormone in the management of polycystic ovary syndrome in adolescents. Gynecol Endocrinol 35:974-977

14. Teede H, Misso M, Tassone EC, Dewailly D, Ng EH, Azziz R, Norman RJ, Andersen M, Franks S, Hoeger K, Hutchison S, Oberfield S, Shah D, Hohmann F, Ottey S, Dabadghao P, Laven JSE (2019) Anti-Müllerian Hormone in PCOS: A Review Informing International Guidelines. Trends Endocrinol Metab 30:467-478

15. O'Reilly MW, Taylor AE, Crabtree NJ, Hughes BA, Capper F, Crowley RK, Stewart PM, Tomlinson JW, Arlt W (2014) Hyperandrogenemia predicts metabolic phenotype in polycystic ovary syndrome: the utility of serum androstenedione.J Clin Endocrinol Metab99:1027-1036

16. Gruber N, Modan-Moses D (2021) Menstrual Cycle in Adolescents: Updating the Normal Pattern.J Clin Endocrinol Metab106:e372-e374

17. Neyzi O, Furman A, Bundak R, Gunoz H, Darendeliler F, Bas F (2006) Growth references for Turkish children aged 6 to 18 years.Acta Paediatr95:1635-41

18. Kuczmarski RJ, Ogden CL, Grummer-Strawn LM, Flegal KM, Guo SS, Wei R, Mei Z, Curtin LR, Roche AF, Johnson CL (2000) CDC growth charts: United States.Adv Data8:1-27

19. Yildiz BO, Bolour S, Woods K, Moore A, Azziz R (2010) Visually scoring hirsutism.Hum Reprod Update16:51-64

20. Park AS, Lawson MA, Chuan SS, Oberfield SE, Hoeger KM, Witchel SF, Chang RJ (2010) Serum anti-mullerian hormone concentrations are elevated in oligomenorrheic girls without evidence of hyperandrogenism. J Clin Endocrinol Metab

Page 10/13 
95:1786-1792

21. Caanen MR, Peters HE, van de Ven PM, Jüttner AMFM, Laven JSE, van Hooff MHA, Lambalk CB (2021) Anti-Müllerian Hormone Levels in Adolescence in Relation to Long-term Follow-up for Presence of Polycystic Ovary Syndrome. J Clin Endocrinol Metab 106:e1084-e1095

22. Pinola P, Morin-Papunen LC, Bloigu A, Puukka K, Ruokonen A, Järvelin MR, Franks S, Tapanainen JS, Lashen H (2014) Anti-Müllerian hormone: correlation with testosterone and oligo- or amenorrhoea in female adolescence in a population-based cohort study. Hum Reprod 29:2317-2325

23. Villarroel C, López P, Merino PM, Iñiguez G, Sir-Petermann T, Codner E (2015) Hirsutism and oligomenorrhea are appropriate screening criteria for polycystic ovary syndrome in adolescents. Gynecol Endocrinol 31:625-629

24. Legro RS, Arslanian SA, Ehrmann DA, Hoeger KM, Murad MH, Pasquali R, Welt CK (2013) Endocrine Society. Diagnosis and Treatment of Polycystic Ovary Syndrome: An Endocrine Society Clinical Practice Guideline. J Clin Endocrinol Metab 98:4565-4592

25. Ortega MT, Carlson L, McGrath JA, Kangarloo T, Adams JM, Sluss PM, Lambert-Messerlian G, Shaw ND (2020) AMH is higher across the menstrual cycle in early post-menarchal girls than in ovulatory women.J Clin Endocrinol Metab105:e1762-71

26. Lie Fong S, Laven JSE, Duhamel A, Dewailly D (2017) Polycystic ovarian morphology and the diagnosis of polycystic ovary syndrome: redefining threshold levels for follicle count and serum anti-Müllerian hormone using cluster analysis.Hum Reprod32:1723-1731

27. Villarroel C, Merino PM, López P, Eyzaguirre FC, Van Velzen A, Iñiguez G, Codner E (2011) Polycystic ovarian morphology in adolescents with regular menstrual cycles is associated with elevated anti-Mullerian hormone. Hum Reprod 26:2861-8

28. Amiri M, Tehrani FR, Bidhendi-Yarandi R, Behboudi-Gandevani S, Azizi F, Carmina E (2019) Relationships Between Biochemical Markers of Hyperandrogenism and Metabolic Parameters in Women with Polycystic Ovary Syndrome: A Systematic Review and Meta-Analysis.Horm Metab Res51:22-34

29. Witchel SF, Oberfield S, Rosenfield RL, Codner E, Bonny A, Ibáñez L, Pena A, Horikawa R, Gomez-Lobo V, Joel D, Tfayli H, Arslanian S, Dabadghao P, Garcia Rudaz C, Lee PA (2015) The Diagnosis of Polycystic Ovary Syndrome during Adolescence. Horm Res Paediatr 83:376-389

30. Gupta M, Yadav R, Mahey R, Agrawal A, Upadhyay A, Malhotra N, Bhatla N (2019) Correlation of body mass index (BMI), anti-mullerian hormone (AMH), and insulin resistance among different polycystic ovary syndrome (PCOS) phenotypes - a cross-sectional study.Gynecol Endocrinol35:970-973

\section{Figures}




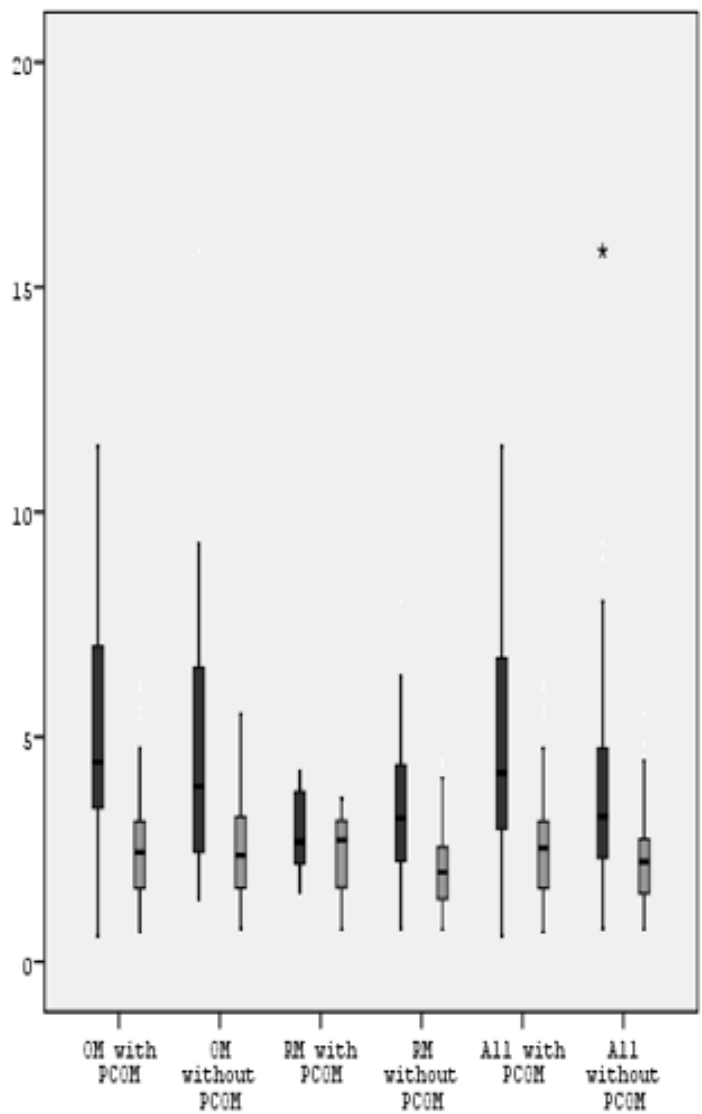

Figurela
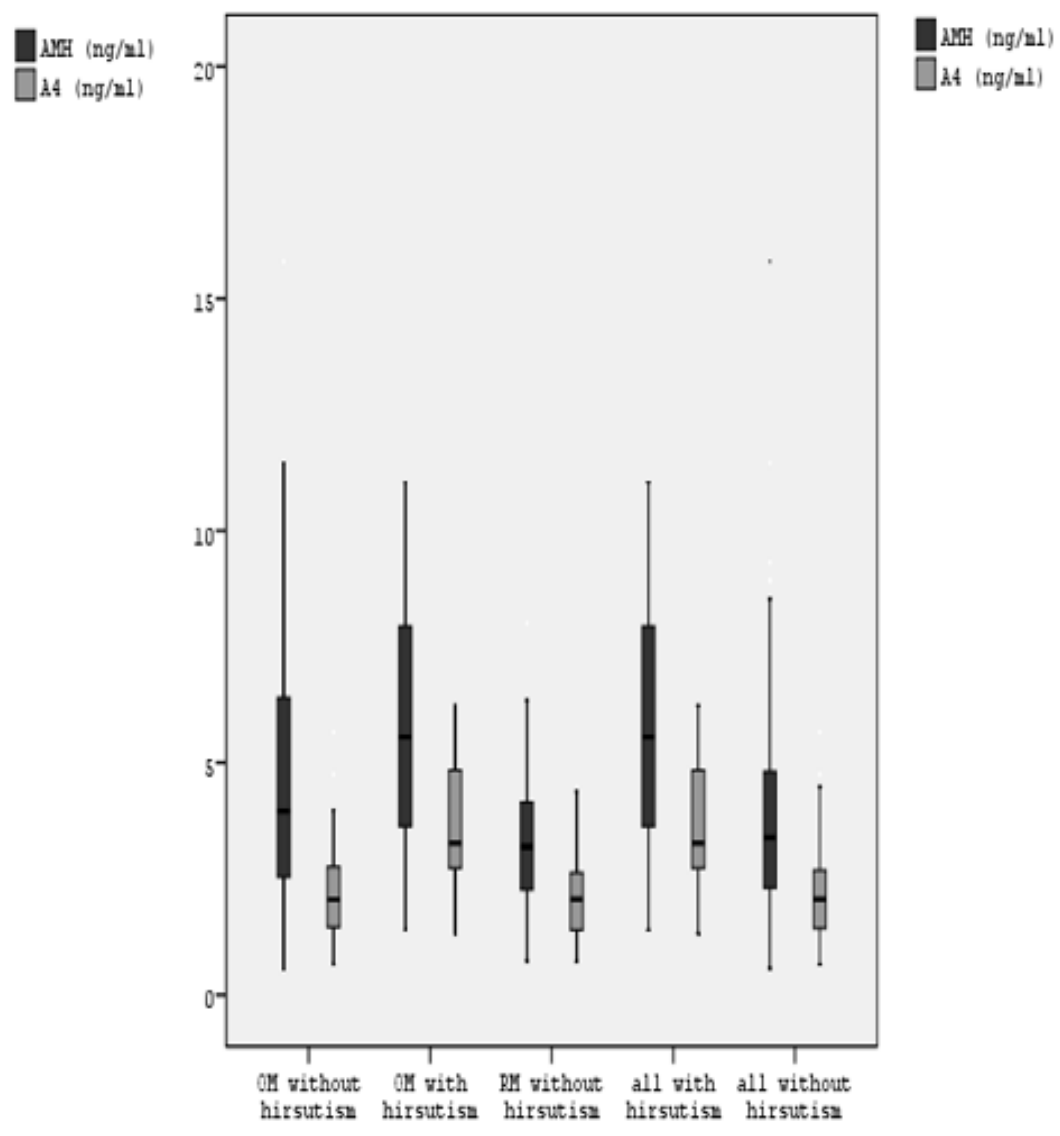

Figure $1 \mathrm{~b}$

\section{Figure 1}

Figure 1a. A4 and AMH levels in girls with or without OM in the presence or absence of PCOM. In adolescent girls with OM who also had PCOM, AMH and A4 levels did not differ significantly from those without PCOM. Similar results were obtained in adolescent girls with regular menstruation. OM: oligomenorrhea, RM: regular menstruation, PCOM: Polycystic ovary morphology.

Figure1b. Androstenedione (A4) and anti-Mullerian hormone (AMH) levels in girls with or without oligomenorrhea in the presence or absence of hirsutism. When oligomenorrhea and hirsutism were concomitant, significantly higher $\mathrm{AMH}$ and $\mathrm{A} 4$ levels were present. 


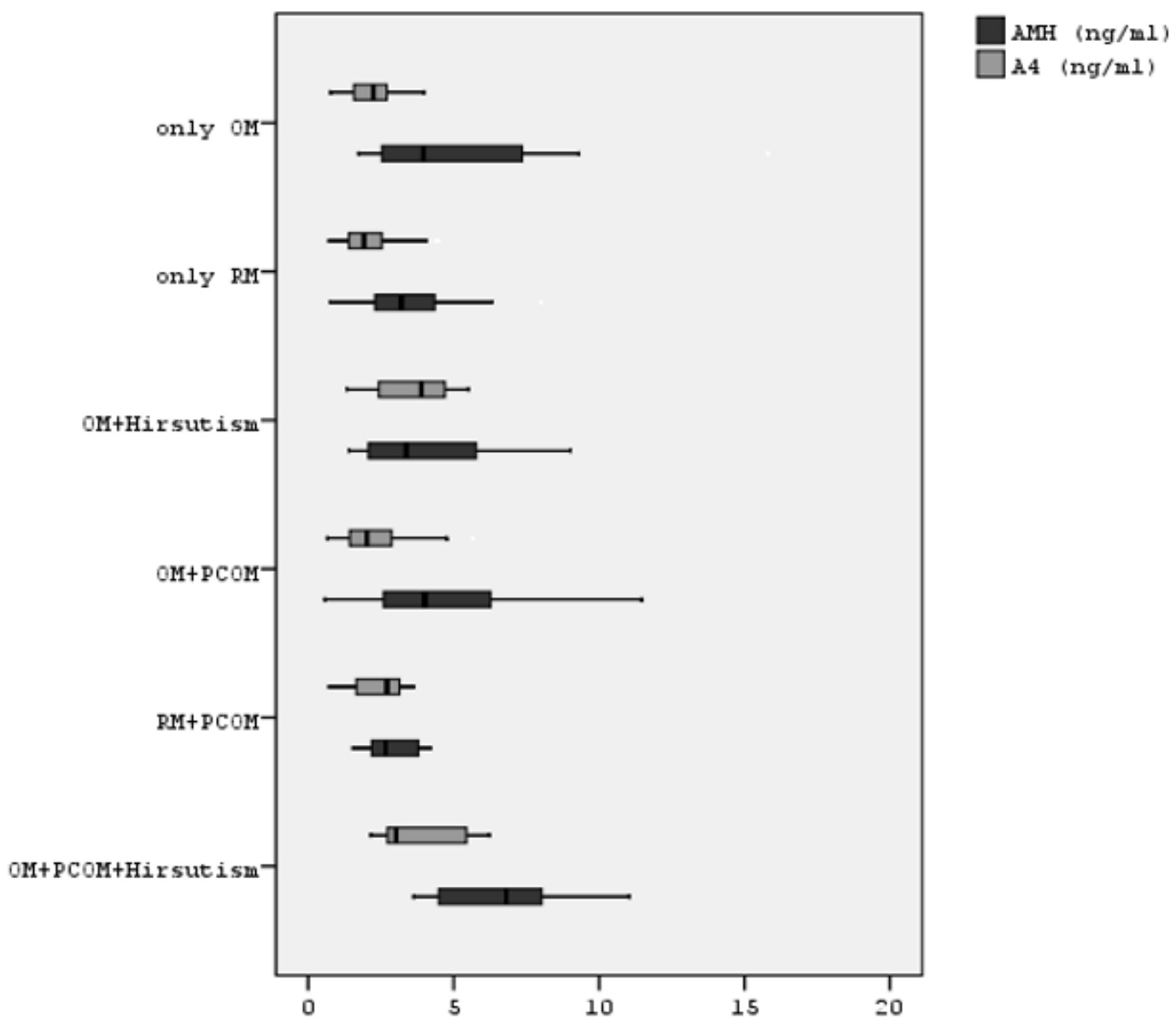

Figure 2

$\mathrm{AMH}$ and A4 levels according to clinical features of PCOS in adolescent girls with and without oligomenorrhea (OM). In adolescents with oligomenorrhea, androstenedione levels are significantly higher in the presence of hirsutism. AMH levels are significantly higher in girls with OM + hirsutism+ PCOM. OM: oligomenorrhea, RM: regular menstruation, Group1: OM or RM only; Group2: OM or RM+ hirsutism; Group3: OM or RM + polycystic ovary morphology (PCOM); Group4: OM or RM + hirsutism+ PCOM, 